17. Андрейко С.С., Иванов О.В., Бикмаева Т.А. Разработка математической модели метода прогнозирования внезапных разрушений пород почвы горных выработок при очистной выемке карналлитового пласта в условиях Верхнекамского месторождения калийных солей // Горный информационноаналитический бюллетень (научно-технический журнал). - 2010. - № 4. - С. 191-196.

18. Андрейко С.С., Иванов О.В. Метод прогноза газодинамических явлений при разработке сильвинитовых пластов Верхнекамского месторождения калийных солей // Горн. информ.-аналит. бюл. - 2009. № 7. - C. 368-373.

19. Андрейко С.С., Иванов О.В., Литвиновская Н.А. Прогнозирование и предотвращение газодинамических явлений из почвы при проходке подготовительных выработок в подработанном массиве соляных пород / С.С. Андрейко,. - Пермь: изд-во ПНИПУ, 2015. - 159 с.

20. Андрейко С.С. Предотвращение газодинамических явлений из почвы горных выработок в условиях применения различных вариантов столбовой системы разработки Третьего калийного пласта на рудниках ОАО «Беларуськалий» // Стратегия и процессы освоения георесурсов: сб. науч. тр. Вып. 15 / ГИ УрО РАН. - Пермь, 2017. - С. 341-345.

21. Андрейко С.С., Шаманский Г.П., Лаптев Б.В. Многомерные статистические критерии классификации газодинамических явлений на рудниках Верхнекамского месторождения калийных солей // Физикотехнические проблемы разработки полезных ископаемых. - 1985. - № 1.-С. 85-94.

\title{
ГАЗОНОСНОСТЬ И ГАЗОДИНАМИЧЕСКИЕ ХАРАКТЕРИСТИКИ ПОРОД IV-П КАЛИЙНОГО ГОРИЗОНТА В УСЛОВИЯХ ШАХТНОГО ПОЛЯ ПЕТРИКОВСКОГО ГОКА
}

\author{
Д.А. Бобров \\ Горный институт УрО РАН, г. Пермь
}

\begin{abstract}
Аннотация: В работе представлены результаты проведённых шахтных экспериментальных исследований по оценке газоносности по свободным газам и газодинамических характеристик пород IV-п калийного горизонта Петриковского ГОКа. По результатам исследований были получены фактические данные о газонасыщенности пород, дана количественная оценка газоносности по свободным газам IV-п калийного пласта и глинисто-соляных пород пласта IV-п Петриковского ГОКа.

Ключевые слова: газоносность, газодинамические характеристики, соляные породы, сильвинитовый пласт, IV-п калийный горизонт.
\end{abstract}

Введение. Петриковское месторождение калийных солей является новым участком будущего ведения подземных горных работ. При вскрытии запасов калийных солей на Петриковском ГОКе в первую очередь будет осуществлена проходка горных выработок околоствольного двора. Проходка указанных выработок в данных условиях будет осуществлена впервые, опыт проведения горных выработок в новых горно-геологических условиях отсутствует. В настоящее время газоносность и газодинамические характеристики пород IV-п калийного горизонта в условиях шахтного поля Петриковского ГОКа малоизучены и требуют проведения научных исследований по их оценке. Как показывает практика ведения горных работ, при подземной разработке месторождений калийных солей существует опасность проявления газодинамических явлений разного вида, которые существенно снижают безопасность ведения горных работ [1-15].

Методика проведения исследований. Исследования проводились с использованием оборудования Центра коллективного пользования «Исследование свойств геоматериалов» при ПНИПУ. Методика реализовывалась путем шахтных инструментальных наблюдений за газовыделениями из скважин диаметром 42 мм, пробуренных в кровлю с одновременным отбором проб свободного газа [16-22].

Исследовательские скважины поинтервально бурились в кровлю выработок и сразу герметизировались на расстоянии 0,5 м от забоя шпура с помощью герметизатора. Газ, 
выделяющийся из стенок и забоя загерметизированной части шпура (скважины), поступает в газоотводящий штуцер, к которому подключается прецизионный портативный цифровой манометр DPI-705 IS, предназначенный для работы в лабораторных и «полевых» условиях.

C помощью DPI-705 IS определяется начальная скорость газовыделения в скважине по давлению, создаваемому газом, проходящим через откалиброванное отверстие капилляра, а также определяется приращение давления газов в скважине в течение 30 секунд после ее герметизации, т.е. начальное газовое давление. По этой величине с помощью заранее построенных графиков зависимости $\boldsymbol{X}=\boldsymbol{f}\left(\boldsymbol{P}_{2}\right)$, где $\boldsymbol{X}$ - газоносность пород, $\mathrm{M}^{3} / \mathrm{M}^{3} ; \boldsymbol{P}_{2}-$ величина начального газового давления, определяются показатели газоносности. Давление газа в массиве рассчитывалось отдельно для каждого интервала по длине скважины в каждом конкретном случае. Прибором DPI-705 IS замеряется скорость истечения газов из шпуров, секундомером фиксируется время изменения скорости.

Полученный объем выделившихся из шпура газов соотносится с объемом зоны дренирования вокруг шпура. Всего было выбрано четыре зоны исследования газоносности и газодинамических характеристик. Произведено 64 замеров газоносности и газодинамических характеристик соляных пород. Исследования проводились с использованием оборудования ЦКП «Центр исследования свойств геоматериалов» ПНИПУ.

Результаты исследований. В процессе проведенных исследований по изучению газоносности пород были получены следующие результаты.

Исследовательская зона № 1 сложена чередованием слоев сильвинита и средне- и крупнозернистой каменной солью с вкрапленностью оранжево-красного сильвинита и карналлита. Газоносность пород в интервале от 1 до 5 м не превышала $0,12 \mathrm{~m}^{3} / \mathrm{m}^{3}$ (Рис. 1). Это говорит о том, что соляные породы IV-п калийного горизонта в кровле выработки относятся к мало газоносным. Начальная скорость газовыделения составляет 0,22 л/мин., давление - 0,190 МПа. В интервалах бурения от 5 до 9 м на участке исследования № 1 газоносность пород составляла от 0,12 до $0,14 \mathrm{~m}^{3} / \mathrm{M}^{3}$. Значение такой газодинамической характеристики, как начальная скорость газовыделения, в данном интервале не превышает 0,06 л/мин, давление составляет 0,190 МПа. Данный интервал приурочен к 0 и 1 сильвинитовым слоям, состоящим из разнозернистой сильвинит-карналлитовой породы оранжево-красного цвета с серым оттенком и кристаллов синего галита.
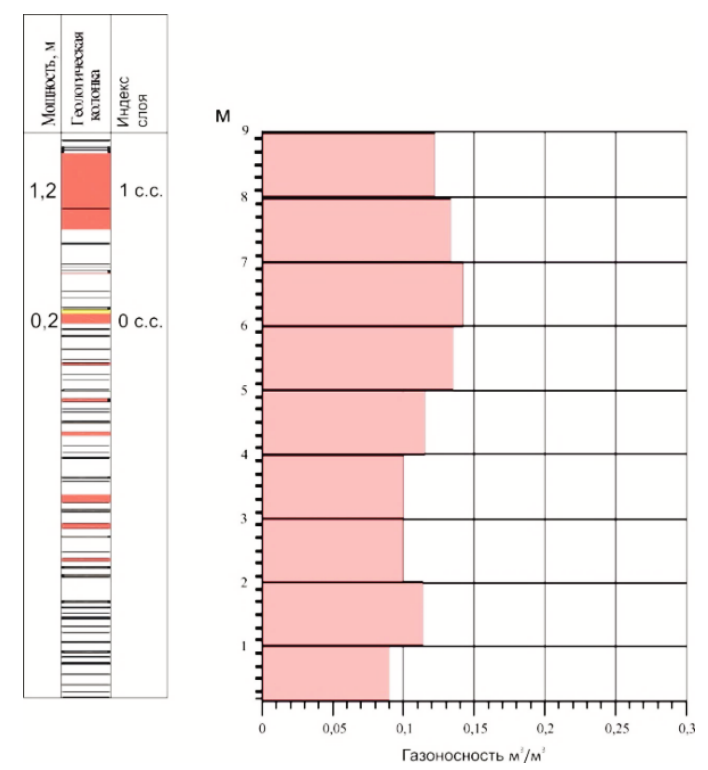

Рис. 1. Газоносность пород, слагающих и перекрывающих промышленный пласт IV-п в зоне исследования № 1

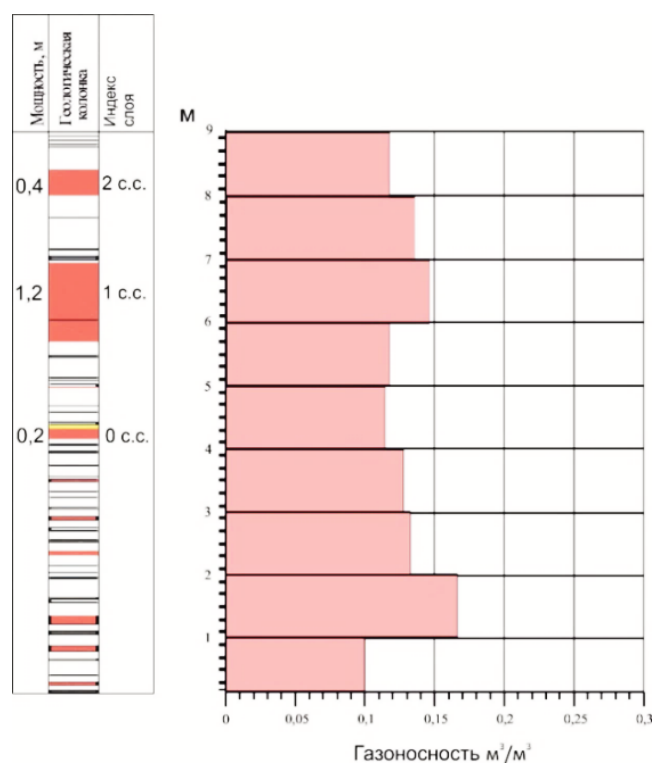

Рис. 2. Газоносность пород, слагающих и перекрывающих промышленный пласт IV-п в зоне исследования № 2 
Исследовательская зона № 2 сложена чередованием слоев сильвинита и разнозернистой каменной солью с вкрапленностью розовато-красного сильвинита и красного карналлита. Также наблюдаются кристаллы синего галита. Газоносность пород составляет от 0,11 до $0,17 \mathrm{~m}^{3} / \mathrm{M}^{3}$ (Рис. 2). Наибольшая газоносность приурочена к прослоям сильвинита, расположенным ниже 0 сильвинитового слоя на 4 м. Данные породы являются мало газоносными. Значения такой газодинамической характеристики, как начальная скорость газовыделения из загерметизированного шпура, на интервале бурения от 1 до 2 м составляла 0,11 л/мин. На всех остальных интервалах измерений в исследовательских шпурах скорость газовыделения не превышала 0,07 л/мин, что также является «фоновым» значением для калийных пластов Старобинского месторождения калийных солей. Максимальное давление на всем интервале исследования не превышает 0,191 МПа.

Исследовательская зона № 3 сложена чередованием слоев красного сильвинита и разнозернистой каменной солью с вкрапленностью розовато-красного сильвинита и красного карналлита. Также наблюдаются кристаллы синего галита. Газоносность пород в зоне исследования № 3 составляет от 0,12 до $0,13 \mathrm{~m}^{3} / \mathrm{m}^{3}$ (Рис. 3). Данные породы являются малогазоносными. Значения такой газодинамической характеристики как начальная скорость газовыделения из загерметизированного шпура на интервале бурения от 1 до 4,5 м не превышала 0,08 л/мин. На интервале исследования от 4,5 до 5,5 м скорость газовыделения составила 0,24 л/мин. Максимальное давление на всех интервалах измерений в исследовательском шпуре не превышало 0,190 МПа.

Исследовательская зона № 4 сложена чередованием слоев сильвинита и разнозернистой каменной солью с вкрапленностью розовато-красного сильвинита и красного карналлита. Также наблюдаются кристаллы синего галита. Газоносность составляет от 0,11 до $0,19 \mathrm{~m}^{3} / \mathrm{M}^{3}$ (Рис. 4). Максимальные значения газоносности приурочены к 0 сильвинитовому слою. Значения такой газодинамической характеристики, как начальная скорость газовыделения из загерметизированного шпура, на интервале бурения от 1,0 до 1,7 м составила 0,21 л/мин. На интервале исследования от 1,7 до 6,0 м скорость газовыделения не превышала 0,14 л/мин. Максимальное давление на всех интервалах измерений в исследовательской скважине не превышало 0,191 МПа. Газоносность пород в исследовательской скважине № 5 составляет от 0,13 до $0,15 \mathrm{~m}^{3} / \mathrm{m}^{3}$. Данные породы являются малогазоносными. Начальная скорость газовыделения из загерметизированного шпура на интервале бурения от 1,0 до 5,0 м не превышала 0,09 л/мин. На интервале исследования от 5,0 до 6,0 м скорость газовыделения составила 0,17 л/мин. Максимальное давление на всех интервалах измерений в исследовательском шпуре не превышало 0,190 МПа.
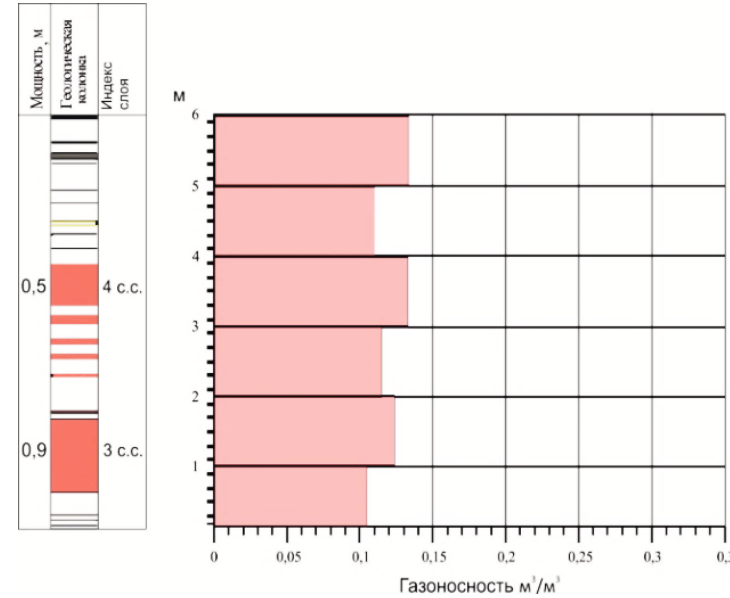

Рис. 3. Газоносность пород, слагающих и перекрывающих промышленный пласт IV-п в зоне исследования № 3

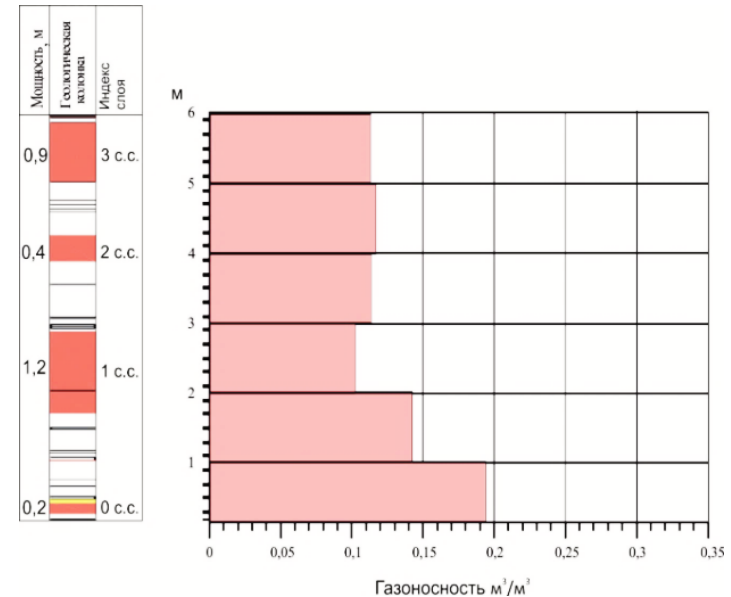

Рис. 4. Газоносность пород, слагающих и перекрывающих промышленный пласт IV-п в зоне исследования № 4 (скважина № 4) 
Заключение. Анализ результатов шахтных экспериментальных научно-исследовательских работ по изучению газоносности по свободным газам и газодинамических характеристик пород IV-п калийного горизонта в камерах питателей и конвейерного ходка в условиях шахтного поля Петриковского ГОКа позволяет сделать следующие выводы.

В четырех исследовательских зонах произведено 64 замера газоносности и газодинамических характеристик соляных пород.

Газоносность пород IV-п калийного горизонта в интервале от кровли выработки камеры питателей (ниже 0 слоя на 6 м.) до слоя соли мощностью примерно 2 м., расположенного выше кровли 4 сильвинитового слоя, не превышает максимально допустимых значений для пластов Старобинского месторождения калийных солей.

Максимальное значение газоносности $\left(0,19 \mathrm{~m}^{3} / \mathrm{M}^{3}\right)$ приурочено к 0 сильвинитовому слою и зафиксировано в исследовательской скважине № 4, расположенной на 1-м вентиляционном штреке главного южного направления на расстоянии 15 м от сопряжения. Максимальное значение начальной скорости наблюдается в исследовательской скважине № 3 в интервале исследования от 4,5 до 5,5 м и составляет 0,24 л/мин. Начальное газовое давление в массиве пород во всех исследовательских скважинах не превышает 0,191 МПа.

Газоносность и газодинамические характеристики пород, расположенных ниже 0 слоя (соль), не превышает $0,17 \mathrm{~m}^{3} / \mathrm{M}^{3}$, начальная скорость газовыделения составляет 0,11 л/мин, давление - 0,191 МПа.

Исследование выполнено при финансовой поддержке Программы ФНИ, проект № 0422-2019-0007-С-01 (регистраџионный номер темы НИОКТР: AAAA-A19-119091690020-0).

Исследование выполнено при финансовой поддержке РФФИ в рамках научного проекта № 18-05-00371 а «Газодинамические явления на калийных рудниках: внезапные разрушения кровли и почвы выработок»

\section{БИБЛИОГРАФИЧЕСКИЙ СПИСОК}

1. Проскуряков Н.М., Ковалев О.В., Мещеряков В.В. Управление газодинамическими процессами в пластах калийных руд. - М.: Недра. -1988. - 239 с.

2. Андрейко С.С. Проблемы безопасной разработки калийных пластов: цели, тенденции и результаты // Моделирование стратегии и процессов освоения георесурсов: материалы междунар. конф. и науч. сес. ГИ УрО РАН. - Пермь, 2003. - С. 115-118.

3. Андрейко С.С. Результаты исследований по прогнозированию и предотвращению газодинамических явлений на Верхнекамском и Старобинском месторождениях калийных солей // Стратегия и процессы освоения георесурсов: материалы ежегод. науч. сес. ГИ УрО РАН по результатам НИР в 2006 г. Пермь, 2007. - С. 137-139.

4. Андрейко С.С. Современное состояние проблемы газодинамических явлений на Верхнекамском месторождении калийных солей // Стратегия и процессы освоения георесурсов: материалы ежегод. науч. сес. ГИ УрО РАН по результатам НИР в 2009 г. - Пермь, 2010. - С. 211-213.

5. Андрейко С.С., Иванов О.В., Нестеров Е.А. Борьба с газодинамическими явлениями при разработке Верхнекамского и Старобинского месторождений калийных солей // Научные исследования и инновации. - 2009. - Т. 3, № 4. - С. 34-37.

6. Андрейко С.С., Иванов О.В. Метод прогноза газодинамических явлений при разработке сильвинитовых пластов Верхнекамского месторождения калийных солей // Горн. информ.-аналит. бюл. - 2009. № 7. - С. $368-373$.

7. Андрейко С.С. Газодинамические явления в калийных рудниках: методы прогнозирования и способы предотвращения: учеб. пособие. - Пермь: Изд-во. ПГТУ, 2007. - 208 с.

8. Андрейко С.С., Иванов О.В., Литвиновская Н.А. Прогнозирование и предотвращение газодинамических явлений из почвы при проходке подготовительных выработок в подработанном массиве соляных пород / С.С. Андрейко,. - Пермь: изд-во ПНИПУ, 2015. - 159 с.

9. Andreiko S., Baryakh A., Lobanov S., Fedoseev A. Geo mechanical Estimation of Danger of Gas-Dynamic Failure During Potash Deposits Mining /// ISRM European Rock Mechanics Symposium (EUROCK). 2017. - V. 191. - P. 954-961. 
10. Барях А.Б., Андрейко С.С., Федосеев А.К. О механизме локализации очагов газодинамических явлений в почве сильвинитовых пластов // Вестн. ПНИПУ: Геология. Нефтегазовое и горное дело. - 2017. - T. 16, № 3.- C. 247-254. DOI: 10.15593/2224-9923/2017.3.5.

11. Андрейко С.С., Лукьянец Е.В., Литвиновская Н.А., Нестеров Е.А., Бобров Д.А., Поляков А.Л., Лутович Е.А. Параметры профилактической дегазации пород почвы горных выработок при слоевой отработке третьего калийного пласта на рудниках ОАО «Беларуськалий» // Вестн. ПНИПУ: Геология. Нефтегазовое и горное дело. - 2017. - Т. 16, № 3.- С. 280-290. DOI: 10.15593/2224-9923/2017.3.9.

12. Andreyko S.S., Lyalina T.A. Rockburst from floors // Soils and Rocks. - 2019. - V. 42, 1. - P. 77-82. DOI: 10.28927/SR.421077.

13. Андрейко С.С. Современное состояние проблемы газодинамических явлений на действующих и вводимых в эксплуатацию калийных рудниках // Горное эхо. - 2019. - № 2 (75). - С. 82-89. DOI: 10.7242/echo.2019.2.20.

14. Андрейко С.С., Иванов О.В., Нестеров Е.А. Исследование способов предотвращения внезапных отжимов призабойной части соляных пород // Горный журнал. - 2018. - № 6. - C.30-34. DOI: 10.17580/gzh.2018.06.06.

15. Андрейко С.С., Литвиновская Н.А., Сиренко Ю.Г., Чаянов А.Б. Предотвращение газодинамических явлений из почвы горных выработок при различных вариантах столбовой системы разработки на рудниках ОАО «Беларуськалий» // Горн. журн. - 2018. - № 8. - С. 29-33. DOI: 10.17580/gzh.2018.08.02.

16. Барбиков Д.В., Андрейко С.С., Иванов О.В., Бобров Д.А. Оценка газодинамических характеристик горных пород Краснослободского разлома // Горн. журн. - 2018. - № 8. - С. 38-42. DOI: 10.17580/gzh.2018.08.04.

17. Андрейко С.С., Литвиновская Н.А. Локальный прогноз зон, опасных по газодинамическим явлениям из почвы горных выработок пласта АБ на южной части шахтного поля БКПРУ -4 Верхнекамского месторождения калийных солей // Горный информационно-аналитический бюллетень (научнотехнический журнал). - 2013. - № 4. - С. 205-211.

18. Андрейко С.С., Иванов О.В., Нестеров Е.А., Головатый И.И., Береснев С.П. Исследование газоносности соляных пород третьего калийного пласта на шахтном поле Краснослободского рудника // Горн. журн. - 2013. - № 6. - С. 69-73.

19. Тараканов В.А., Головатый И.И., Береснев С.П., Андрейко С.С., Иванов О.В. Исследование газоносности пород пласта третьего калийного горизонта Старобинского месторождения // Горн. журн. 2010. - № 8. - С.25-27.

20. Медведев И.И., Полянина Г.Д. Газовыделения на калийных рудниках. - М.: Недра, 1974. - 163 с.

21. Земсков А.Н., Кондрашев П.И., Травникова Л.Г. Природные газы калийных месторождений и меры борьбы с ними. - Пермь: Тип. Купца Тарасова, 2008. - 412 с.: ил., табл.

22. Лейбензон Л.С. Движение природных жидкостей и газов в пористой среде // Собрание трудов. - М., 1951-1955. -4 т.

УДК 622.253

DOI:10.7242/echo.2020.2.19

\title{
АНАЛИЗ ЭФФЕКТИВНОСТИ ПРИМЕНЕНИЯ ГАЗОВЫХ КАЛОРИФЕРОВ ПРЯМОГО НАГРЕВА В УСЛОВИЯХ ШАХТ И РУДНИКОВ
}

\author{
Д.А. Бородавкин, А.В. Зайцев \\ Горный институт УрО РАН, г. Пермь
}

\begin{abstract}
Аннотация: В данной работе рассматриваются существующие способы нагрева воздуха в холодный период года и производится их сравнение. Приводится анализ изменения компонентного состава нагреваемого воздуха на примере действующей системы прямого нагрева воздуха. Выявляется дополнительный критерий, оказывающий влияние на экономическое обоснование таких систем.

Ключевые слова: система воздухоподготовки, газовая горелка, прямой нагрев воздуха, энергоэффективность, предельно допустимая концентрация.

Свежий воздух, поступающий в подземные горные выработки в холодный период, следует нагревать до температуры не менее $+2{ }^{\circ} \mathrm{C}$ для обогрева воздухоподающего ствола. Для этого шахты и рудники оборудуются системами воздухоподготовки. На сегодняшний день в качестве воздухонагревателей наибольшую популярность получили
\end{abstract}

